\title{
Study on Admissible Displacement Calculation Method of Double-Column Piers
}

\author{
Kairui Wang, Xiuli Xu, Weiguo Huang, and Weiqing Liu
}

\begin{abstract}
Because of the load capacity design method cannot guarantee the structure to achieve the prospective plastic deformation or ductility requirement, so the displacement of pier should be calculated in the seismic design. This paper focuses on the ductile deformation and allowable displacement of reinforced concrete double-column piers under earthquake action. Based on the nonlinear analysis software ABAQUS, the seismic response and failure state of reinforced concrete double-column piers under transverse earthquake are studied through incremental dynamic analysis (IDA) method. According to the relationship between material constitutive and limit state, the displacements of piers are obtained in three different (the slightly damage limit state, controlled damage limit state and controlled collapse limit state). Besides the pier height and tie beam are also consider in the analysis. The relationship between the displacement angle and the strain of double-column piers under the transverse earthquake action is analyzed and a simplified formula of admissible displacement of pier is proposed. Through verification, this simplified formula is simple and accurate, and can be used in the preliminary design.
\end{abstract}

Index Terms-Double-column piers, admissible displacement of pier, performance state, concrete damaged plastic model.

\section{INTRODUCTION}

A large number of bridges damages after earthquake [1]-[3] show that: Inadequate strength of bridge does not necessarily lead to collapse, even serious damage. As long as the initial strength of bridge meets the basic requirement, the increase of inelastic deformation will not induce excessive decrease in strength, and bridge will still meet service requirement with a small amount of repair costs. However, if the inelastic deformation cause a sharp strength decrease, the severe failure or even collapse of bridges are usually observed. Therefore, the control of pier displacement through ductility design is the key to avoid pier collapse.

At present, the studies on the deformation calculation of reinforced concrete column mainly focus on the deformation bent capacity [4]-[7] and axial load capacity [8] in yield and ultimate state, residual displacement [9] and the relationship between ductility deformation bent capacity and restrain stirrup [10], [11]. But few studies had been done on the deformation calculation of different damage states involved in the whole failure process. To complete and accurately define

Manuscript received January 22, 2017; revised April 1, 2017. This work was supported in part by the National Natural Science Foundation of China (Grant No.51178220 and 51108234), the Transportation Science and Technology project (2013Y12), and the Science and technology support program (BE2014716), Jiangsu, China.

The authors are with Nanjing Tech University, Nanjing, China (e-mail kairuiking@sina.com, njxuxiuli@163.com, colinering@126.com, wqliu@njtech.edu.cn). the performance level of the component, it is necessary to study the whole failure process.

In the Guidelines for Seismic Design of Highway Bridges [12] (abbreviated as Guidelines) of China, the allowable top displacement of single-pier less than $30 \mathrm{~m}$ is given under the horizontal and vertical seismic actions, but for doublecolumn piers and bent piers under seismic action are not clearly given. The present researches are mainly for the preliminary design of top displacement of double-column piers, which is not applicable for the double-column piers with tie beam for the different position of plastic hinge.

In this paper, the ductility deformation and admissible displacement of reinforced concrete double-column piers under earthquake are studied. The limit displacement of pier is determined. Through the comparative analysis of various factors, a reasonable and simple calculation formula of permissible displacement of double-column piers is obtained, which is conducive to the improvement of bridge seismic design and code.

\section{Deformation BENT CAPACITY OF REINFORCED CONCRETE PIERS}

\section{A. Guidelines for Seismic Design of Highway Bridges}

Guidelines require that the deformation of B-type and C-type bridge piers need to be checked, and a definite calmn pier is obtained:

$$
\Delta_{\mathrm{u}}=\frac{1}{3} H^{2} \phi_{y}+\left(H-\frac{L_{P}}{2}\right) \theta_{u}
$$

$\theta_{u}$ is the maximum admissible angle in the plastic hinge region:

$$
\theta_{u}=L_{p}\left(\phi_{u}-\phi_{y}\right) / K
$$

where, $K$ is the ductile safety factor, taking as $2.0 ; \phi_{y}$ and $\phi_{u}$ is yield curvature and limit curvature of the cross-section respectively.

The longitudinal admissible displacement of double-column piers and bent piers are the same as that of the single pier. The transverse admissible displacements of piers are required to be nonlinearly analyzed. When any plastic hinge of pier reaches its maximum admissible angle, the horizontal displacement at the bent cap is the admissible displacement.

\section{B. Caltrans Seismic Design Criteria}

A more detailed provision of pier displacement is 
stipulated in Caltrans Seismic Design Criteria (abbreviated as Caltrans) [13], and the double-column piers are divided into three forms: rigid bent cap, flexible bent cap, flexible bent cap with flexible foundation. The specific deformation situations are in Fig. 1.

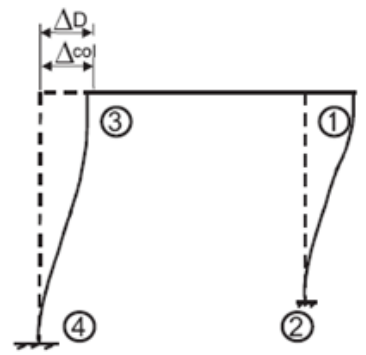

(a) Rigid bent cap

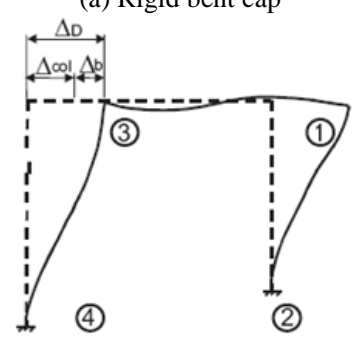

(b) Flexible bent cap

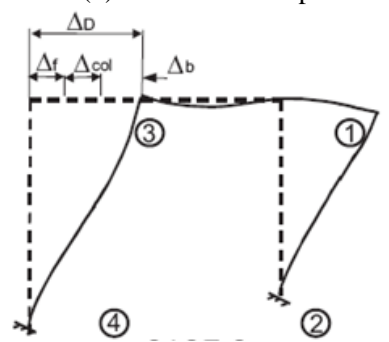

(c) Flexible bent cap with flexible foundation

Fig. 1. Transverse displacement and plastic hinge of double-column piers.

The displacement capacity, $\Delta_{c}$ of any column may be idealized as one or two cantilever segments presented in Equations (3-7) and (8-11), respectively. See Fig. 2 and Fig. 3 for details.

$$
\begin{gathered}
\Delta_{c}=\Delta_{Y}^{c o l}+\Delta_{p} \\
\Delta_{Y}^{\mathrm{col}}=\frac{L^{2}}{3} \times \phi_{Y} \\
\Delta_{p}=\theta_{p} \times\left(L-\frac{L_{p}}{2}\right) \\
\theta_{p}=L_{p} \times \phi_{p} \\
\phi_{p}=\phi_{u}-\phi_{Y} \\
\Delta_{C 1}=\Delta_{Y 1}^{c o l}+\Delta_{p 1}, \quad \Delta_{Y 2}=\Delta_{Y 2}^{c o l}+\Delta_{p 2} \\
\Delta_{Y 1}^{\mathrm{col}}=\frac{L_{1}^{2}}{3} \times \phi_{Y 1}, \quad \Delta_{Y 2}^{\mathrm{col}}=\frac{L_{2}^{2}}{3} \times \phi_{Y 2} \\
\theta_{\mathrm{p} 1}=L_{p 1} \times \phi_{p 1}, \quad \theta_{\mathrm{p} 2}=L_{p 2} \times \phi_{p 2} \\
\phi_{p 1}=\phi_{u 1}-\phi_{Y 1}, \quad \phi_{p 2}=\phi_{u 2}-\phi_{Y 2}
\end{gathered}
$$

where: $L$ is distance from the point of maximum moment to the point of contra-flexure; $L_{p}$ is equivalent plastic hinge length; $\Delta_{c}$ is idealized plastic displacement capacity due to rotation of the plastic hinge; $\Delta_{p}$ is idealized yield displacement of the column at the formation of the plastic hinge; $\Delta_{p}{ }^{c o l}$ is idealized yield curvature; $\phi_{Y}$ is idealized plastic curvature capacity (assumed constant over $L_{p}$ ); $\phi_{p}$ is curvature capacity at the failure limit state; $\theta_{p}$ is Plastic rotation capacity.

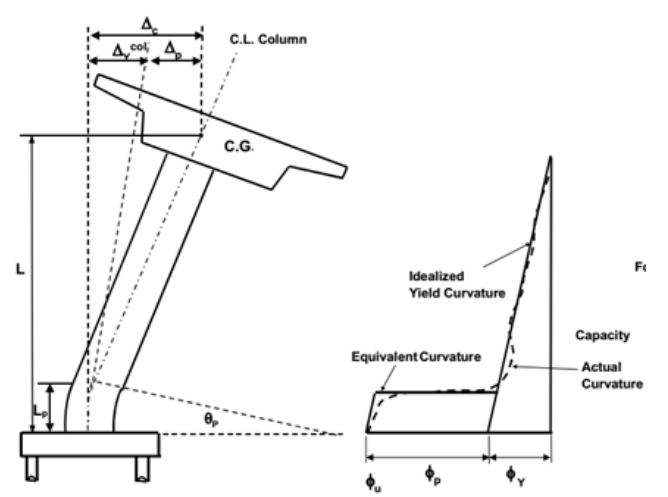

Fig. 2. Displacement capacity - cantilever column with fixed base
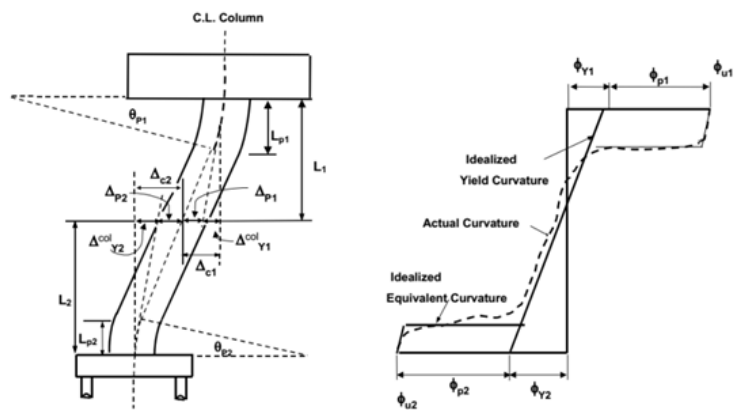

Fig. 3. Displacement capacity - framed column, assumed as fixed-fixed.

\section{NUMERICAL ANALYSIS MODEL}

In this paper, ABAQUS is used to analyze the performance of double-column piers. The Concrete Damaged Plasticity Model (CDP model) is adopted as the constitutive model of concrete. The 3D solid linear reduction unit C3D8R and 3D beam element T3D2 are used to simulated concrete and rebar. The applied seismic wave is obtained by converting the response spectrum from Guidelines.

Nonlinear station analysis, nonlinear dynamic analysis and IDA are often used to analyze the nonlinear seismic response characteristics of structure. IDA method can reflect the seismic performance under different earthquake intensity, and can make a more comprehensive and realistic evaluation of the seismic bent capacity of structure. So IDA method is adopted in this paper. The model parameters in this paper are based on the parameters of a typical bridge. The basic parameters of model are shown in Table I.

\section{FORMULA SIMULATION}

The displacement angle - rebar strain curve of typical double-column piers is shown in Fig. 4.

Fig. 4 shows that the displacement angle-rebar strain curve of typical double-column piers is approximately linear. But the displacement angle is discrete with the rebar strain between 0.04 and 0.09 . Therefore, curve is divided into two parts (0-0.04 and 0.04-0.09) to fit, seen in Fig. 5. 


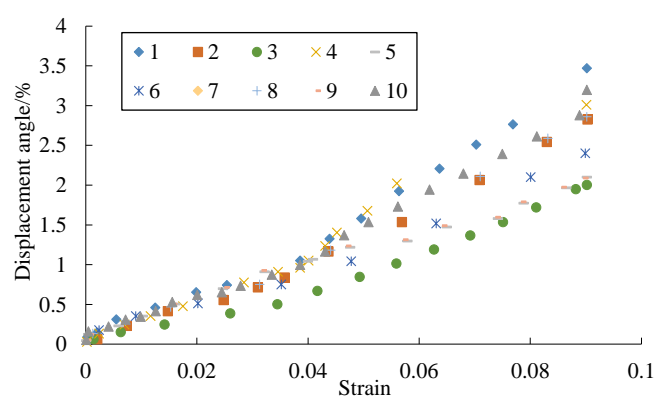

Fig. 4. Displacement angle - rebar strain curve of typical double-column piers.

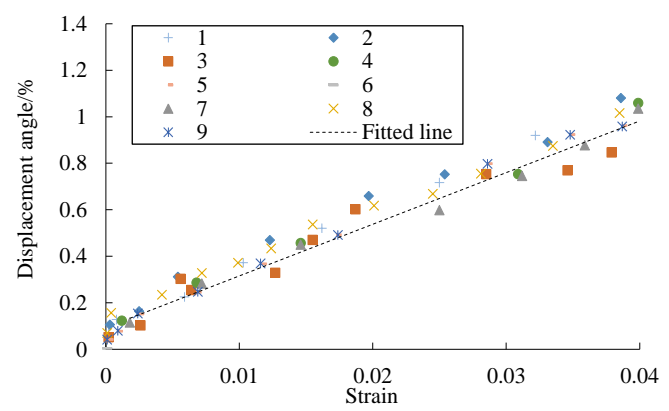

a. Rebar strain 0-0.04

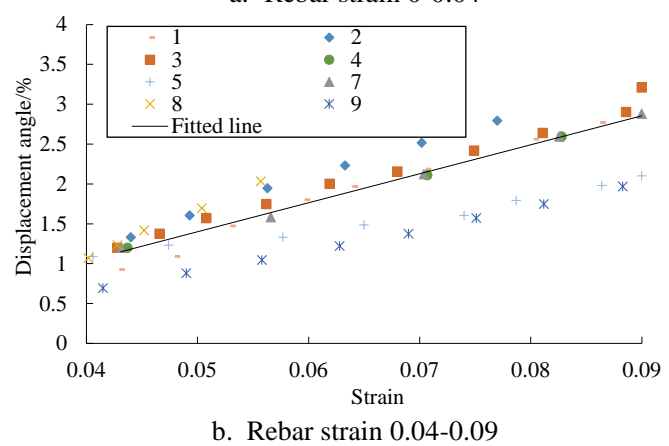

Fig. 5. Displacement angle - rebar strain curve.

From Fig. 5, it can be seen that the relation between displacement angle and strain is linear, so it is assumed that the relationship formula is:

$$
\theta=(A B C) k \varepsilon_{S}
$$

First taking $k_{l}=24.63$ and $k_{2}=45.89$, then based on the $10 \mathrm{~m}$ double-column piers without tie beam, the coefficients $A, B$ and $C$ are determined by the relationship between displacement angle and compression ratio, pier height, stirrup ratio.

$A$ is defined as the axial compression ratio coefficient. According to the previous research, it was found that the displacement angle of double-column piers with the compression ratio of $0.1,0.2$ and 0.3 is decreased by $20 \%$. Thus, $A$ can be expressed in the form as $A=0.8^{\frac{(\eta-0.1)}{0.1}}$, which $\eta$ is the compression ratio.

$B$ is defined as the pier height coefficient. According to the previous research, it was found that the displacement angles of double-column piers with pier height of $5 \mathrm{~m}, 10 \mathrm{~m}$ and $20 \mathrm{~m}$ are almost the same in each performance state, while the displacement angles of $30 \mathrm{~m}$ double-column piers are $40 \%$ smaller than that of $20 \mathrm{~m}$. Therefore, $B$ can be expressed in the form as $B=0.6^{\left(\frac{L-20}{10}\right)}$, where $L$ is the pier height, $L \geq 20 \mathrm{~m}$.

$C$ is defined as is the stirrup ratio. As the stirrup ratio affects core concrete compressive strain, and the compressive strain of the double-pier concrete is less than control the compressive strain - 0.004 under transverse earthquake, so $C$ is equal to 1 .

Finally, after adjusting the values of $k_{1}$ and $k_{2}$, the displacement angle formula of double-column piers under the transverse earthquake is obtained:

$$
\theta=28.6 \times \varepsilon_{S}, \varepsilon_{s}=0 \sim 0.04
$$

$\theta=38 \times\left(0.8^{\frac{(\eta-0.1)}{0.1}}\right) \times\left(0.6^{\left(\frac{L-20}{10}\right)}\right) \times \varepsilon_{S}, \varepsilon_{S}=0.04 \sim 0.09$

where: $\varepsilon_{s}$ is the rebar strain; $\varepsilon_{s}=0.015$ means slightly damage; $\varepsilon_{s}=0.06$ means controlled damage; $\varepsilon_{s}=0.09$ means controlled collapse. Table II shows the displacements of each model.

\begin{tabular}{|c|c|c|c|c|c|c|c|}
\hline No & $\begin{array}{c}\text { Tie beam } \\
\text { number }\end{array}$ & $\begin{array}{c}\text { Pier } \\
\text { Height } / \mathrm{m} \\
\end{array}$ & $\begin{array}{c}\text { Section } \\
\text { Diameter/m }\end{array}$ & $\begin{array}{c}\text { Rebar } \\
\text { Diameter/m }\end{array}$ & Compression ratio & $\begin{array}{l}\text { Stirrups } \\
\text { ratio/\% }\end{array}$ & $\begin{array}{c}\text { Longitudinal rebar } \\
\text { ratio/\% }\end{array}$ \\
\hline 1 & 1 & 10 & 1.3 & 28 & 0.1 & 0.40 & 0.6 \\
\hline 2 & 0 & 10 & 1.3 & 28 & 0.1 & 0.40 & 0.6 \\
\hline 3 & 0 & 5 & 1.2 & 28 & 0.1 & 0.40 & 0.6 \\
\hline 4 & 2 & 20 & 1.4 & 28 & 0.1 & 0.40 & 0.6 \\
\hline 5 & 3 & 25 & 1.5 & 28 & 0.1 & 0.40 & 0.6 \\
\hline 6 & 3 & 30 & 1.6 & 28 & 0.1 & 0.40 & 0.6 \\
\hline 7 & 0 & 10 & 1.3 & 28 & 0.1 & 0.60 & 0.6 \\
\hline 8 & 0 & 10 & 1.3 & 28 & 0.1 & 0.80 & 0.6 \\
\hline 9 & 0 & 10 & 1.3 & 28 & 0.2 & 0.40 & 0.6 \\
\hline 10 & 0 & 10 & 1.3 & 28 & 0.3 & 0.40 & 0.6 \\
\hline
\end{tabular}

TABLE I: PARAMETERS OF MODEL

\begin{tabular}{|c|c|c|c|c|c|c|c|c|}
\hline \multirow{3}{*}{ No } & \multicolumn{6}{|c|}{ Performance status } & \multicolumn{2}{|c|}{ Displacement angle formula } \\
\hline & \multicolumn{2}{|c|}{ Slightly damage } & \multicolumn{2}{|c|}{ Controlled damage } & \multicolumn{2}{|c|}{ Controlled collapse } & \multirow{2}{*}{$0 \leq \varepsilon_{\mathrm{s}} \leq 0.04$} & \multirow{2}{*}{$0.04 \leq \varepsilon_{\mathrm{s}} \leq 0.09$} \\
\hline & $\mathrm{D} / \mathrm{m}$ & $\mathrm{DA} / \%$ & $\mathrm{D} / \mathrm{m}$ & $\mathrm{DA} / \%$ & $\mathrm{D} / \mathrm{m}$ & $\mathrm{DA} / \%$ & & \\
\hline 1 & 0.044 & 0.444 & 0.181 & 1.809 & 0.304 & 3.040 & $20.15 \varepsilon_{\mathrm{s}}+0.115$ & $41.05 \varepsilon_{\mathrm{s}}-0.638$ \\
\hline 2 & 0.053 & 0.5 & 0.208 & 2.1 & 0.35 & 3.5 & $24.63 \varepsilon_{\mathrm{s}}+0.131$ & $45.89 \varepsilon_{\mathrm{s}}-0.685$ \\
\hline 3 & 0.021 & 0.421 & 0.108 & 2.156 & 0.150 & 3.008 & $24.16 \varepsilon_{\mathrm{s}}+0.07$ & $37.83 \varepsilon_{\mathrm{s}}-0.312$ \\
\hline
\end{tabular}

TABLE II: THE TOP DISPLACEMENTS OF PIERS OF EACH MODEL IN EACH PERFORMANCE STATUS 


\begin{tabular}{ccccccccc}
4 & 0.105 & 0.527 & 0.365 & 1.825 & 0.641 & 3.204 & $23.41 \varepsilon_{\mathrm{s}}+0.130$ & $38.45 \varepsilon_{\mathrm{s}}-0.437$ \\
5 & 0.123 & 0.49 & 0.342 & 1.37 & 0.526 & 2.10 & $24.77 \varepsilon_{\mathrm{s}}-0.1$ & $19.72 \varepsilon_{\mathrm{s}}+0.24$ \\
6 & 0.079 & 0.265 & 0.341 & 1.136 & 0.608 & 2.027 & $14.75 \varepsilon_{\mathrm{s}}+0.051$ & $27.78 \varepsilon_{\mathrm{s}}-0.507$ \\
7 & 0.046 & 0.462 & 0.169 & 1.693 & 0.287 & 2.866 & $22.44 \varepsilon_{\mathrm{s}}+0.096$ & $36.57 \varepsilon_{\mathrm{s}}-0.454$ \\
8 & 0.042 & 0.416 & 0.140 & 1.404 & 0.240 & 2.398 & $16.96 \varepsilon_{\mathrm{s}}+0.149$ & $31.61 \varepsilon_{\mathrm{s}}-0.460$ \\
9 & 0.046 & 0.464 & 0.174 & 1.741 & 0.287 & 2.871 & $23.85 \varepsilon_{\mathrm{s}}+0.098$ & $36.30 \varepsilon_{\mathrm{s}}-0.419$ \\
10 & 0.047 & 0.474 & 0.174 & 1.742 & 0.287 & 2.871 & $23.99 \varepsilon_{\mathrm{s}}+0.092$ & $40.10 \varepsilon_{\mathrm{s}}-0.627$ \\
\hline \hline
\end{tabular}

Note: Displacement and Displacement angle of pier are abbreviated as D and DA in Table II-Table III.

\section{VERIFICATION}

The results comparison between formulas $(13,14)$ and the numerical method are shown in Table III. It can been seen that the errors between these two results are small, less than engineering error of $10 \%$, and the average error is $6.5 \%$.

TABLE III: RESUlt COMPARISON BETWEEN THE PROPOSED FORMULA AND THE NUMERICAL METHOD

\begin{tabular}{|c|c|c|c|c|c|c|c|c|}
\hline \multirow{3}{*}{ No } & \multicolumn{6}{|c|}{ Proposed formula } & \multirow{3}{*}{$\begin{array}{c}\text { Numerical } \\
\text { Limit DA /\% }\end{array}$} & \multirow{3}{*}{ Error $1 \%$} \\
\hline & \multicolumn{2}{|c|}{$\begin{array}{c}\text { Slight damage } \\
\text { limit state }\end{array}$} & \multicolumn{2}{|c|}{ Controlled damage limit state } & \multicolumn{2}{|c|}{ Controlled collapse limit state } & & \\
\hline & $\mathrm{D} / \mathrm{m}$ & $\mathrm{DA} / \%$ & $\mathrm{D} / \mathrm{m}$ & $\mathrm{DA} / \%$ & $\mathrm{D} / \mathrm{m}$ & $\mathrm{DA} / \%$ & & \\
\hline 1 & 0.0429 & 0.429 & 0.199 & 1.992 & 0.324 & 3.240 & 3.500 & 7.4 \\
\hline 2 & 0.0429 & 0.429 & 0.199 & 1.992 & 0.291 & 2.907 & 3.040 & 4.4 \\
\hline 3 & 0.0214 & 0.429 & 0.100 & 1.992 & 0.158 & 3.150 & 3.008 & 4.7 \\
\hline 4 & 0.0858 & 0.429 & 0.388 & 1.938 & 0.630 & 3.150 & 3.204 & 1.7 \\
\hline 5 & 0.1073 & 0.429 & 0.398 & 1.594 & 0.563 & 2.252 & 2.100 & 7.2 \\
\hline 6 & 0.1287 & 0.429 & 0.407 & 1.357 & 0.616 & 2.052 & 2.027 & 1.2 \\
\hline 7 & 0.0429 & 0.429 & 0.159 & 1.594 & 0.274 & 2.736 & 2.866 & 4.5 \\
\hline 8 & 0.0429 & 0.429 & 0.127 & 1.275 & 0.219 & 2.189 & 2.398 & 8.7 \\
\hline 9 & 0.0429 & 0.429 & 0.159 & 1.594 & 0.274 & 2.736 & 2.871 & 4.7 \\
\hline 10 & 0.0429 & 0.429 & 0.159 & 1.594 & 0.274 & 2.736 & 2.871 & 4.7 \\
\hline
\end{tabular}

The proposed formula is compared with the transverse permissible displacements formula of the double-column

piers of Caltrans, and the results are shown in Table IV.

TABLE IV: RESUlt COMPARISON BETWEEN THE PROPOSED FORMULA AND CALTRANS SEISMIC DESIGN CRITERIA

\begin{tabular}{|c|c|c|c|c|c|}
\hline \multirow{3}{*}{ No } & \multirow{2}{*}{\multicolumn{2}{|c|}{$\frac{\text { Proposed formula }}{\text { Controlled damage limit state }}$}} & \multirow{2}{*}{\multicolumn{2}{|c|}{ Caltrans formula }} & \multirow{3}{*}{ Error $1 \%$} \\
\hline & & & & & \\
\hline & $\mathrm{D} / \mathrm{m}$ & $\mathrm{DA} / \%$ & Admissible D /m & $\mathrm{DA} / \%$ & \\
\hline 1 & 0.324 & 3.240 & 0.358 & 3.583 & 10.6 \\
\hline 2 & 0.291 & 2.907 & 0.278 & 2.781 & 4.3 \\
\hline 3 & 0.158 & 3.150 & 0.147 & 2.934 & 6.8 \\
\hline 4 & 0.630 & 3.150 & 0.657 & 3.284 & 4.2 \\
\hline 5 & 0.563 & 2.252 & 0.980 & 3.265 & 59.1 \\
\hline 6 & 0.616 & 2.052 & 0.231 & 2.314 & 15.4 \\
\hline 7 & 0.274 & 2.736 & 0.205 & 2.046 & 6.6 \\
\hline 8 & 0.219 & 2.189 & 0.238 & 2.378 & 13.1 \\
\hline 9 & 0.274 & 2.736 & 0.214 & 2.142 & 21.7 \\
\hline 10 & 0.274 & 2.736 & 0.328 & 3.283 & 20.1 \\
\hline
\end{tabular}

As can be seen from Table IV, the difference between these two methods is quite different when the pier height is high. The main reason is as follows: The formula of Caltrans assumes an ideally situation that the plastic hinge at the fixed end of the pier reach the limit rotation angle at the same time, but in fact, they are in order occurrence. The tie beam is destroyed first, and then the bottom rebar reaches the ultimate strain in the simulation of this paper. Besides, the $P-\Delta$ effect of higher pier has a great influence. Therefore, the top displacement angle of higher pier calculated by using the proposed formula is small.

\section{CONCLUSION}

Considering the effect of pier height and tie beam parameters on load capacity and deformation capacity of double-column piers, the finite element model is adopted to analyze the elastic-plastic analysis of reinforced concrete double-column piers. The influence of each parameter is summarized and the allowable displacement of the reinforced 
concrete double-column pier under each performance condition is obtained. And the relationship between displacement angle and reinforcement strain of double-column pier is fitted. The results are compared with the results obtained by numerical analysis and the formulas in Caltrans Seismic Design Criteria. The results show that the formula is simple and can be used for preliminary design.

\section{ACKNOWLEDGMENT}

The writers are grateful for the support from the National Natural Science Foundation of China (Grant No.51178220 and 51108234), the Transportation Science and Technology project (2013Y12) and the Science and technology support program (BE2014716), Jiangsu, China.

\section{REFERENCES}

[1] J. Li, T. Peng and Y. Xu, "Damage investigation of girder bridges under the Wenchuan earthquake and corresponding seismic design recommendations," Earthquake Engineering and Engineering Vibration, vol. 7, no. 4, pp. 337-344, Dec 2008.

[2] Q. Han, X. Du, Z. Li, L. Li, and J. Zhao, "Seismic damage of highway bridges during the 2008 Wenchuan earthquake," Earthquake Engineering and Engineering Vibration, vol. 8, no. 2, pp. 263-273, Jun 2009.

[3] C. C. Lin, H. H. Hung, K.Y. Liu, and J. F. Chai, "Reconnaissance report of 0512 China Wenchuan earthquake on bridges," in Proc. 14th World Conference on Earthquake Engineering, Beijing, China, 2008.

[4] T.B. Panagiotakos, "Deformations of Reinforced Concrete Members at Yielding and Ultimate," Aci Structural Journal, vol. 98, no. 2, pp. 135-147, Mar 2001.

[5] M.P. Berry, "Performance Models for flexural damage in reinforced concrete Columns," Pacific Earthquake Engineering Research Center, University California, Berkeley, 2003.

[6] H. Jiang, and X. Lv, "Lateral displacement estimation for RC columns in different seismic damage states," Journal of Earthquake Engineering and Engineering Vibration, vol. 28, no. 2, pp. 46-50, Apr 2008.

[7] H. Jiang, B. Wang, and X. Lv, "Performance limit states and deformation limits of RC beams and columns," Building Structure, vol 40, no. 1, pp. 10-14, Jan 2010. (in Chinese)

[8] B. Stojadinovic, M. Rand, K R. Mackie, and V. Majstorovic, "Degradation of bridge column axial load capacity with increasing lateral displacement ductility," International Workshop on Seismic Design \& Retrofit of Transportation Facilities, Washington, USA, Apr 2006.

[9] M. Ansari, F. Daneshjoo, and M. S. Mohammadi, "On estimation of seismic residual displacements in reinforced concrete single-column bridges through force-displacement method," International Journal of Civil Engineering, pp. 1-14, Dec 2016.

[10] S. Watson, F.A. Zahn, and R. Park, "Confining reinforcement for high-strength concrete columns," Aci Structural Journal, vol. 98, no. 3 , pp. 395-406, May-Jun 2004.

[11] Ko. S H, "Displacement ductility of circular RC column according to the spacing of spirals," Journal of the Korea Institute for Structural Maintenance \& Inspection, vol. 17, no. 2, pp.71-82, Mar 2013.

[12] Guidelines for Seismic Design of Highway Bridges, JTG/T B02-01-2008, Ministry of Transport of the People 's Republic of China 2008.

[13] Caltrans Seismic Design Criteria, Version 1.6, California Department of Transportation, 2010.

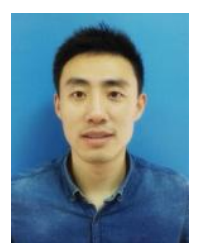

Kairui Wang was born in Jiangsu, China, in October 1986. He received his master degree from the Nanjing Tech University 2013 in Nanjing of China. His main research fields are bridge seismic and seismic control, bridge life cycle information technology (BrIM).

He pursues a degree of $\mathrm{PhD}$ at Nanjing Tech University right now. His main papers are shown as follow: K. Wang, X. Xu, X. Li, Z. Li, and W. Liu,
"Shake-Table study of a continuous girder bridge with lead rubber bearing under high intensity earthquake," Bridge construction, vol. 46, no. 5, pp. 59-64, 2016; Z. Li, K. Wang, X. Xu, S. Wang, X. Li, and K. Wang, "Seismic response analysis and optimization design of extra wide bridge," Earthquake Engineering and Engineering Dynamic, vol. 34, no. 2, pp. 120-128, 2014 Z. Li, F. Ge, X. Xu, and K. Wang, "Finite element simulation and experimental study of property for elastomeric pad bearing," Journal of Southeast University, vol. 43, no. 6, pp. 1299-1304, 2013.

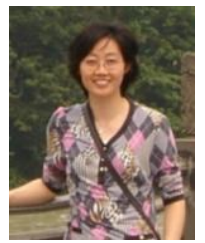

Xiuli Xu was born in Jiangsu, China, in April 1963. She received the $\mathrm{PhD}$ from the Southeast University 2009 in Nanjing of China. Her main research fields are bridge seismic and seismic control, bridge life cycle information technology (BrIM), steel bridge standardization design and construction technology. She has been teaching at Nanjing Tech University since 1985. She is currently a professor in the department of bridge engineering at college of Civil Engineering. She had undertaken a number of research projects, such as the key basic research and development program of China, the National Natural Science Foundation of China, the Transportation Science and Technology project and the Science and technology support program. Her main papers are shown as follow: X. Xu and W. Liu et al., "A new formula of impact stiffness in linear viscoelastic model for pounding simulation," Shock and virbration, 2016, vol. 4, pp. 1-7; $\mathrm{X}$. $\mathrm{Xu}$ and $\mathrm{W}$. Liu, R. Wang et al., "Full-bridge Aero-elastic model wind-tunnel tests for long-span cable Stayed bridge with viscous dampers," Transportation Research Board 90th Annual Meeting, 2011; X. Xu, W. Liu, Z. Wang et al., "A matter of restraint: Damping the Hangzhou bay bridge," Bridge Design and Engineering, 2005.

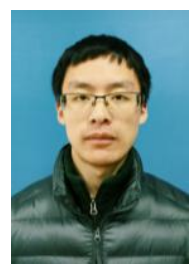

Weiguo Huang was born in Jiangsu, China, in June 1992. He received the bachelor degree from the Nanjing Tech University in Nanjing of China in 2014. His main research fields are bridge seismic design and vibration control, bridge stochastic vibration.

He pursues a degree of $\mathrm{PhD}$ at Nanjing Tech University right now.

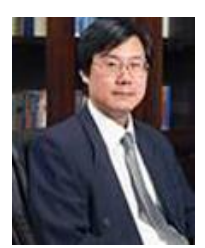

Weiqing Liu was born in Jiangsu, China, in March 1964. He received the $\mathrm{PhD}$ from the Southeast University 1995 in Nanjing of China. His main research fields are structural damping control, composite structure, modern wood structure, concrete structure.

He has been teaching at Nanjing Tech University since 1988 . He is currently a professor in the department of bridge engineering at college of Civil Engineering and the vice President of Nanjing Tech University. He had undertaken a number of research projects, such as the key basic research and development program of China, the key projects of National Natural Science Foundation of China, the National Natural Science Foundation of China. His main papers are shown as follow: L. Wang, W. Liu, Y. Fang et al., "Axial crush behavior and energy absorption capability of foam-filled GFRP tubes manufactured through vacuum assisted resin infusion process," Thin-Walled Structures, vol. 98, pp. 263-273, 2016; W. Liu, F. Zhang, L. Wang et al., "Flexural performance of sandwich beams with lattice ribs and a functionally multilayered foam core," Composite Structures, vol. 152, pp. 704-711, 2016; J. Wang, W. Liu, L. Wang et al., "Estimation of main cable tension force of suspension bridges based on ambient vibration frequency measurements," Structural Engineering \& Mechanics, vol. 56, no. 6, pp. 939-957, 2015.

Prof. Liu is the executive member of Anti-Seismic System International Society (ASSISi), the vice chairman of the Chinese Modern Timber Architecture Technology Industry Association, the director of Chinese Architecture Society and Mechanics Society. 